\title{
Perception of synthetic nasal consonants in initial and final syllable position
}

\author{
LEAH S. LARKEY, JERRY WALD, and WINIFRED STRANGE \\ University of Minnesota, Minneapolis, Minnesota 55455
}

\begin{abstract}
Identification and discrimination of synthesized syllable-initial and syllable-final nasal con-

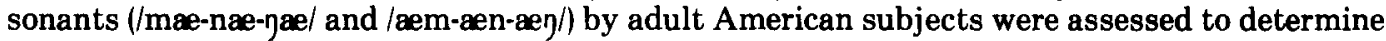
(1) whether place-of-articulation contrasts in nasals, cued only by second and third formant transition variations, were perceived categorically, and (2) if linguistic experience affected the perception of this acoustic dimension. In two experiments, subjects produced consistent identification functions with sharp boundaries between familiar phoneme categories. Corresponding discrimination functions showed "peaks" of relatively accurate perception for cross-category comparison pairs, indicating categorical perception. Identification consistency and discrimination accuracy were inferior for the $/ \mathrm{n} /-\mathrm{m} / \mathrm{c}$ contrast in the unfamiliar (and phonologically inappropriate) syllable-initial condition compared to the familiar syllable-final condition. No such difference was found in identification and discrimination of the acoustically comparable oral stop consonant contrast $/ \mathrm{d} / / \mathrm{g} / \mathrm{g} /$ in syllable-initial and syllable-final position. These results provide evidence that perception of linguistically relevant acoustic dimensions by adults is constrained, at least in part, by their familiarity with those acoustic (and phonetic) contrasts in specific phonological contexts.
\end{abstract}

Research on the perception of consonants has shown that the ability of adult listeners to discriminate acoustic differences in speech stimuli depends on the linguistic relevance of those differences. That is, speech patterns that differ along a (phonetically relevant) acoustic dimension are discriminated with high accuracy only if the patterns are identified as different phonemes within the listener's language. Other acoustic patterns that differ to the same degree, but are identified as tokens of the same consonant, are discriminated only slightly better than chance. Such an acoustic dimension is said to be perceived categorically. (See Liberman, Cooper, Shankweiler, \& Studdert-Kennedy, 1967; Pisoni, 1973; Studdert-Kennedy, 1976.)

This research was supported by grants to James J. Jenkins and Winifred Strange from the National Institute of Mental Health (MH-21153) and to the Center for Research in Human Learning from the National Institute of Child Health and Human Development (HD-01136) and the National Science Foundation (BNS 7503816). During the course of this research, Leah Larkey and Jerry Wald were supported by a training grant to the Center for Research in Human Learning (HD-0098). The authors wish to thank Alvin M. Liberman for allowing them to use the facilities of Haskins Laboratories to construct stimulus materials under a grant from NICHD. They also wish to thank James J. Jenkins for his advice and editorial comments, Johnnie Williams for preparation of the manuscript, and Vince Berg for preparation of the figures. Requests for reprints should be addressed to: Winifred Strange, Center for Research in Human Learning, 205 Elliott Hall, University of Minnesota, 75 East River Road, Minneapolis, Minnesota 55455.
Of particular interest for the research reported here are the experiments dealing with contrasts in the place-of-articulation of consonants. It has been shown that the direction and extent of the transition of the second oral speech formant $(\mathrm{F} 2)$ provides a sufficient cue to differentiate /b/ from /d/ from /g/ in synthetic stop consonant + vowel (CV) syllables for certain vowels, such as / $\mathfrak{a} /$ (Liberman, Delattre, Cooper, \& Gerstman, 1954). The direction and extent of the third formant (F3) transition was shown to be a cue for the place-of-articulation of liquids, $/ \mathrm{r} /$ and // (O'Connor, Gerstman, Liberman, Delattre, \& Cooper, 1957), and also an important second cue for stops (Harris, Hoffman, Liberman, Delattre, \& Cooper, 1958).

Studies of the identification and discrimination of two-formant synthetic CV patterns have demonstrated that $\mathrm{F} 2$ transition differences in oral stop consonants are perceived categorically (Liberman, Harris, Hoffman, \& Griffith, 1957; Mattingly, Liberman, Syrdal, \& Halwes, 1971). Typical discrimination functions were marked by "peaks" of highly accurate discrimination of pairs whose members were drawn from different phoneme categories, (i.e., from across an identification boundary) and "troughs" of poor discrimination of equal-interval pairs drawn from within a single phoneme category. Pisoni (1973) replicated these results using three-formant synthetic stimuli in which F2 and F3 transitions varied.

The present study investigated the perception of differences in place-of-articulation as cued by $F 2 / F 3$ 
transitions in synthetic nasal stop consonants $/ \mathrm{m} /$, $/ \mathrm{n} /$, and $/ \mathrm{\eta} /$. When in syllable-initial position, nasality is cued primarily by the presence of low-frequency energy (a major nasal formant) which precedes the onset of the formants and continues inte the following vowel. However, the place-of-articulation of nasal consonants that distinguishes $/ \mathrm{m} /$ from $/ \mathrm{n} /$ from $/ \mathrm{g} / \mathrm{can}$ be cued by the shape of the F2 and F3 transitions, just as for oral stop consonants (Delattre, 1958; Liberman et al, 1954; Malécot, 1956). Thus, it is possible to generate a series of synthetic nasal + vowel stimuli that are identified as instances of $/ \mathrm{m} \mathfrak{} /, / \mathrm{n} \mathfrak{x} /$, and $/ \eta \mathfrak{a} /$, in which the stimuli differ only in F2 and F3 transitions. In addition, a series of vowel + nasal syllable-/am/, /æn/, and $/ \mathfrak{y}_{\mathrm{y}} /$-can be produced by synthesizing patterns that are mirror images of the syllable-initial stimuli.

There are two reasons for our interest in the perception of these speech patterns. First, they provide an opportunity to investigate the perception of the nasal manner class. Studies of phonetic distinctions in oral stops, fricatives, liquids, and vowels have produced reliable findings regarding categorial perception (e.g., Abramson \& Lisker, 1970; Cutting \& Rosner, 1974; Fry, Abramson, Eimas, \& Liberman, 1962; Mattingly et al., 1971' ; Miyawaki, Strange, Verbrugge, Liberman, Jenkins, \& Fujimura, 1975). Previous unpublished experiments of nasal consonants, however, yielded ambiguous results (Garcia, Notes 1 and 2$)^{2}{ }^{2}$ A recent study by Miller and Eimas (1977) investigated only one of the possible place-of-articulation distinctions $(/ \mathrm{m} /-/ \mathrm{n} /$, but not $/ \mathrm{n} /-/ \eta /)$.

A second reason for our interest in the nasals is that they enable us to ask about the effects of linguistic experience upon the perception of phonetic contrasts (or, more specifically, the acoustic differences underlying those contrasts). In English, $/ \mathrm{m} /, / \mathrm{n}$ ' and $/ \eta /$ may each occur in syllable-final position, as in "ram," "ran," and "rang." However, the velar nasal $/ \eta /$, cannot occur in syllable-initial position in English, e.g., "met" and "net," but not "nget." Thus, there is a "hole in the code" created by the phonotactic rules of English, since all possible contrasts are not utilized in all syllabic contexts. ${ }^{3}$

We were interested in whether the perception of the acoustic differences that differentiate place-of-articulation would reflect this "hole in the code." Specifically, would the perception of syllable-initial and syllablefinal $/ \eta /$ differ? If highly accurate perception of acoustic dimensions depends upon familiarity with specific phonetic contrasts along those dimensions, then we might expect relatively poor discrimination between tokens of $/ \mathrm{n} /$ and $/ \mathrm{y} /$ in syllable-initial position.

Evidence for the influence of linguistic experience on perception of phonetic contrasts comes largely from cross-language studies (Abramson \& Lisker,
1970; Miyawaki et al., 1975). Each of these studies compared the discrimination by two groups of subjects of an acoustic dimension underlying a contrast that is used in the language of one group (i.e., is phonemic) but is not used in the language of the other group. The typical categorical "peaks" in discrimination were produced only by the subjects for whom the contrast was phonemic. Subjects in the other language group showed uniformly poor discrimination both within phoneme categories and across the "foreign" identification boundary.

A within-language study by Abramson and Lisker (1970) provides some additional evidence that categorical perception of acoustic dimensions is influenced by highly specific experience with particular phonetic contrasts. In the Thai language, a voicing distinction is phonemic for stop consonants with labial and alveolar place-of-articulation but not for stops with velar place-of-articulation. Results of discrimination tests of two native Thai speakers showed categorical peaks at the identification boundary for labial and alveolar synthetic stimuli; however, discrimination of the comparable velar series produced no clear peak. These data suggest that good discrimination of acoustic differences in speech stimuli requires familiarity with the specific phonetic contrasts cued by those differences.

In the present experiments, we were interested in whether discrimination of the acoustic dimension differentiating place-of-articulation in nasals would reflect subjects' familiarity with phonetic contrasts in specific syllable contexts. The first experiment asked three questions: (1) Were the syllable-initial and (mirror-image) syllable-final synthetic nasals highly identifiable? That is, were the synthetic patterns "good" representations of nasal phonemes? (2) Were the initial and final nasals perceived categorically? (3) Were there specific effects of syllable position on the perception of the velar nasal, $/ \eta /$ ? In particular, was the contrast between $/ \mathrm{n} /$ and $/ \mathrm{g} /$ discriminated less well for syllable-initial nasals than for syllable-final nasals?

The second experiment was a replication and extension of the first. In addition to testing a second group of subjects on the nasal stimuli, two series of oral stop consonants-a syllable-initial and a syllable-final series-were also presented in a withinsubjects design. This allowed for a more detailed comparison of the effects of syllabic context and linguistic familiarity on the perception of place contrasts. The contrast between alveolar and velar oral stops, $/ \mathrm{d} /-\mathrm{g} /$, is distinguished acoustically by the same changes in $F 2$ and $F 3$ as for the nasal $/ \mathrm{n} /-$ $/ \eta /$ distinction. However, for the stops, the contrast is phonologically appropriate and familiar in both syllabic positions. 


\section{EXPERIMENT 1}

\section{Method}

Stimulus materials. The stimuli were produced on the Minnesota Glace-Holmes parallel-resonance synthesizer. The syllable-initial nasal series consisted of 10 three-formant nasal $+/ \mathbf{a} /$ syllables. The 10 stimuli were identical in all respects except for the initial transitions of the second and third oral formants. Figure 1 presents a schematization of the series. The narrow lines represent the variable portions of each stimulus. The starting frequency of the second formant (F2) was increased in steps of approximately $120 \mathrm{~Hz}$ from $1,048 \mathrm{~Hz}$ for Stimulus 1 to $2,123 \mathrm{~Hz}$ for Stimulus 10 . The starting frequency of the third formant (F3) increased in approximately $180-\mathrm{Hz}$ steps from 2,113 to $2,848 \mathrm{~Hz}$ over the first five stimuli, then decreased in the same steps from Stimulus 6 to Stimulus 10 . Transitions of F2 and F3 were $40 \mathrm{msec}$ in duration and were linear functions from their starting loci to the steadystate frequencies of 1,765 and $2,480 \mathrm{~Hz}$, respectively.

As shown in Figure 1, the constant nasal formant was centered at $265 \mathrm{~Hz}$; its onset occurred $100 \mathrm{msec}$ prior to the onset of $\mathrm{F} 2$ and F3. The constant steady-state first formant (F1) began $40 \mathrm{msec}$ after the onset of the upper formants; it was centered at $720 \mathrm{~Hz}$.

The amplitude of the nasal and Fl formants was modulated during the transition portion of each syllable. Coincident with the onset of F2 and F3, the amplitude of the nasal formant was decreased in a positively accelerated function from its full amplitude ( $-9 \mathrm{~dB}$ relative to $\mathrm{F} 1$ at full amplitude) to its offset $70 \mathrm{msec}$ later. The amplitude of $\mathrm{F} 1$ increased in a decelerated function to its full amplitude $20 \mathrm{msec}$ after its onset. F2 and F3 rose to full amplitude within the first $10 \mathrm{msec}$ of onset; during the steady-state vowel portion, F2 and F3 amplitudes were -2 and $-7 \mathrm{~dB}$ relative to $\mathrm{F} 1$, respectively.

The stimuli were digitized using the Pulse Code Modulation system at Haskins Laboratories, and three kinds of tests were constructed: a familiarization series, two identification tests, and a discrimination test. The familiarization series consisted of the 10 stimuli, recorded in order from 1 to 10 . Each identification test consisted of 10 blocks of the 10 stimuli randomly arranged within each block. Within each block, the interstimulus interval was $2 \mathrm{sec}$; the interblock interval was $5 \mathrm{sec}$. Two such randomizations were recorded on audio tape for presentation to subjects.

The oddity discrimination test consisted of triads of stimuli in which two of the three stimuli were identical; the third stimulus differed from these by either one step or two steps. All 17 possible

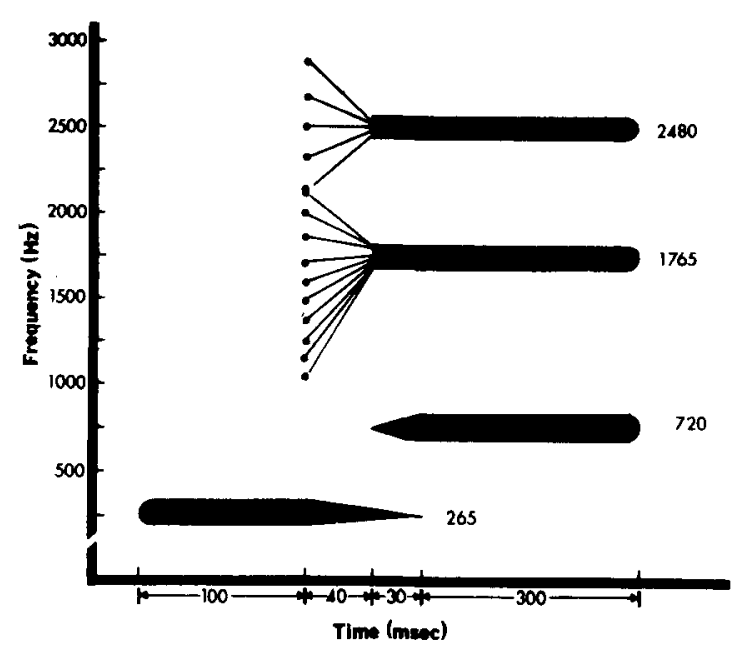

Figure 1. Schematic representation of the nasal stimulus series. The narrow lines indicate variable portions of each syllable. comparisons of the 10 stimuli were made (9 one-step comparisons and 8 two-step comparisons), and each of the permutations of each comparison were included: AAB, ABA, BAA, BBA, BAB, and $\mathrm{ABB}$. The 102 triads $(17 \times 6)$ were recorded in random order, with a 1-sec interstimulus interval and a 3 -sec intertriad interval. This test was divided into two 51-triad subtests for presentation to subjects.

The stimuli and tests as described above were used for the syllable-initial condition. For the syllable-final condition, the taperecorded test sequences were played backwards. As a result, the syllable-final nasal stimuli were exact temporal mirror images of the syllable-initial nasals, and the sequencing of stimuli was reversed.

Subjects. Nine summer-session students at the University of Minnesota participated in this experiment. Each was paid or received extra credit points toward his/her grade. All were normalhearing native English speakers, and none were told the nature of the experiment until after its completion.

Procedure. The subjects were tested in small groups ranging from two to four in number. All groups were tested for 4 days in a sound-attenuated experimental room. The stimuli were presented binaurally via Koss Pro-600A earphones and a Revox tape recorder at a constant listening level for all conditions.

All subjects were presented the syllable-final nasals on the first 2 days of testing and the syllable-initial nasals on the last 2 days. ${ }^{4}$ At the beginning of the first session for each syllable condition, the subjects heard the appropriate familiarization series with no prior instructions and were asked to describe what speech sounds they heard. They were then told that the stimuli consisted of instances of $/ \mathrm{m} /, / \mathrm{n} /$, and $/ \mathrm{n} /$, and the familiarization series was presented again.

Immediately following familiarization, the first identification test (counterbalanced over groups of subjects) was administered. For each stimulus, the subjects were instructed to record on an answer sheet whether they had heard an "m," "n," or "ng" sound. After a brief break, the subjects completed the discrimination test (again with the order of presentation of subtests counterbalanced across groups), in which they indicated on a printed score sheet whether the first, second, or third stimulus in each triad was the "different" one.

On the second day of testing for each syllable condition, the subjects were reminded of what sounds they would hear; they then completed the second identification test and the discrimination test (with the opposite ordering of subtests). Each subject therefore completed two identification tests (20 judgments/ stimulus) and two discrimination tests (12 judgments/comparison pair) for the syllable-final nasals in the first two sessions and an equal number for the syllable-initial nasals on the final 2 days of testing.

\section{Results and Discussion}

Familiarization. As noted above, studies by Garcia (Notes 1 and 2) produced equivocal results pertaining to the categorical perception of nasals because the synthetic nasal stimuli were not heard as speech by all subjects. In the present experiment, all subjects spontaneously reported hearing the familiarization stimuli as speech. For both syllable-initial and syllable-final nasals, all subjects reported hearing $/ \mathrm{m} /$ and $/ \mathrm{n} /$. However, syllable-initial $/ \mathrm{n} /$ was at first reported only as a "third speech-like sound" by several subjects.

Identification. Given that the stimuli were initially perceived as speech, the next question was how the subjects partitioned the stimulus series into the phonetic categories they reported hearing. Such par- 
titions can be defined in terms of functions obtained from the identification tests. The number of times each of the stimuli was identified as each of the three speech sounds was determined for each subject. The place where two identification functions cross defines a phoneme boundary for that subject.

Figure 2 shows the identification functions for the syllable-initial and syllable-final nasals pooled over all nine subjects. As can be seen, the average phonetic boundary between $/ \mathrm{m} /$ and $/ \mathrm{n} /$ occurred close to Stimulus 4 in both conditions. For the syllableinitial nasals, the average $/ \mathrm{n} /-/ \mathrm{\eta} /$ boundary occurred between Stimuli 8 and 9; it occurred between Stimuli 7 and 8 for the syllable-final condition. The relative rightward placement of the syllable-initial $/ \mathrm{n} /-/ \eta$ boundary may reflect a general bias against using the unfamiliar / $\mathfrak{n}$ / response.

These average boundaries reflect quite accurately the results obtained for individual subjects. Figure 3 shows the distribution of $/ \mathrm{m} /-/ \mathrm{n} /$ and $/ \mathrm{n} /-/ \mathrm{\eta} /$ category boundaries for the nine subjects. (One subject's identification function had no evidence of a $/ \mathrm{m} /$ $/ \mathrm{n} /$ boundary in the syllable-initial condition, this same subject and one other had no $/$ næ/ $/-/ \eta \mathfrak{a} /$ boundary; a third subject had no clear $/ \mathfrak{a n} /-/ \mathfrak{a} \eta /$ boundary. Data for these subjects at these boundaries are therefore not included in Figure 3.) This distribution shows that more subjects perceived a category boundary between Stimuli 8 and 9 in the syllable-initial condition than in the syllable-final condition.

The pooled identification functions in Figure 2 show relatively sharp boundaries retween categories. The steepness of the boundary slopes is one indication of the consistency with which subjects identified the stimuli. A second indication of identification consistency is the relative frequency with which stimuli within a category (defined by the appropriate identification boundaries) are identified as a token of that category. For example, the proportion of stimuli between 4 and 7, inclusive, that are labeled /an' on the pooled syllable-final identification function reflects consistency of identification of /æn/. Inconsistency is reflected by the extent to which the curves for the other categories /æm/ and /æy/ rise above

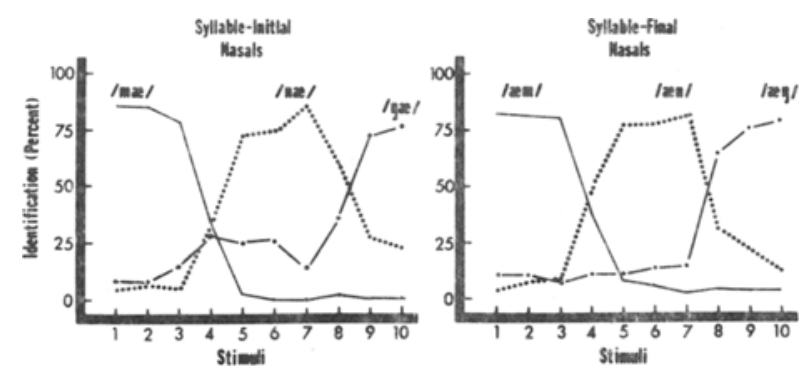

Figure 2. Pooled identification of syllable-initial (left) and syllable-final (right) nasals: Experiment 1.
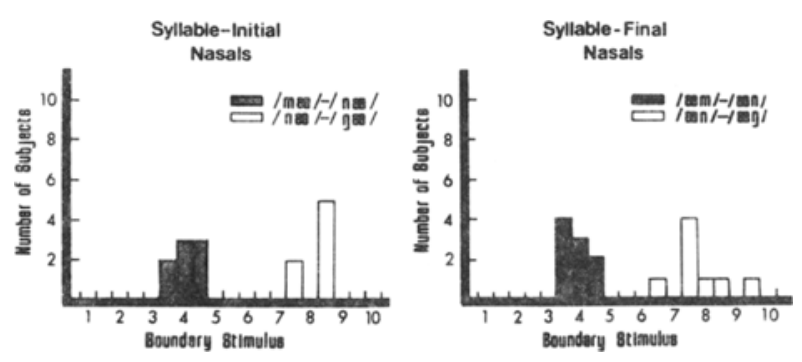

Figure 3. Frequency histogram of subjects' category boundary locations for nasals: Experiment 1.

zero in the /æn/ category. With respect to the $/ \mathrm{n} /$ category, these $/ \mathrm{m} /$ and $/ \mathrm{g} /$ tokens constitute "intrusions."

These two indications of consistency (i.e., relative steepness of slope and relative frequency of labeling stimuli within a phoneme category as tokens of that category) are captured in a measure that was derived for each subject by computing the proportion of stimuli in each category $\mathrm{x}$ that are labeled $\mathrm{x}$. (See Appendix A for a full description of the way this measure was derived.) This measure yields six consistency scores for each subject, one for each phoneme category in each syllable condition. These scores may then be averaged across subjects. The individual subjects' consistency scores and the average consistency scores for the syllable-initial and syllable-final nasals are shown in Table 1.

The average values suggest that the $/ \mathrm{m} /$ category (where no difference due to syllabic condition was expected) is labeled more consistently in initial position than in final position, while the $/ n /$ and $/ \eta /$ categories are labeled more consistently in final position. However, when submitted to statistical analysis, these numerical differences were not significant, perhaps because of the small number of subjects. Patterns of identification consistency are examined more closely in Experiment 2.

In summary, the results of identification tests indicate that most subjects were able to label the tokens of the stimulus series as instances of the three nasal consonants. Tokens within phoneme categories were labeled quite reliably, and boundaries between categories were sharp and, for the most part, monotonic. There was some suggestion that lack of familiarity with the phoneme $/ \eta /$ in syllable-initial position might have affected identification adversely, as shown by the greater number of "intrusions" within the syllable-initial $/ \mathrm{n} /$ category. The consistency scores in Table 1 also suggest an increased ambiguity of the $/ \eta$ / category and the adjacent $/ n$ / tokens for syllableinitial stimuli relative to the final stimuli, although the differences were not statistically significant. In order to determine further the degree to which familiarity affects the perception of the acoustic contrast between $/ \mathrm{n} /$ and $/ \mathrm{g} /$, the results of discrimination tests were examined. 
Table 1

Consistency Scores: Experiment 1

\begin{tabular}{|c|c|c|c|c|c|c|}
\hline & \multicolumn{3}{|c|}{$\begin{array}{c}\text { Syllable-Initial } \\
\text { Nasals }\end{array}$} & \multicolumn{3}{|c|}{$\begin{array}{c}\text { Syllable-Final } \\
\text { Nasals }\end{array}$} \\
\hline & mae & nae & nae & aem & aen & aen \\
\hline Subject 1 & .80 & .71 & .72 & .63 & .57 & .54 \\
\hline Subject 2 & .80 & .61 & .44 & .34 & .69 & .58 \\
\hline Subject 3 & .90 & .63 & .68 & .73 & .73 & .68 \\
\hline Subject 4 & .81 & .78 & & .88 & .67 & .80 \\
\hline Subject 5 & .85 & .69 & .83 & .98 & .94 & 1.00 \\
\hline Subject 6 & 1.00 & .78 & .34 & .96 & .97 & .98 \\
\hline Sulject 7 & .81 & .66 & .34 & .58 & .63 & \\
\hline Subject 8 & & .48 & .56 & .95 & .78 & 1.00 \\
\hline Subject 9 & .98 & .80 & .90 & .85 & .90 & .97 \\
\hline Mean & .87 & .68 & .60 & .77 & .76 & .82 \\
\hline Adjusted Mean & .87 & .68 & .64 & .74 & .76 & .82 \\
\hline
\end{tabular}

Note-A blank indicates that the subject did not identify any stimulus as belonging to this category (see Appendix A). Adjusted means were computed including only subjects for whom both initial and final categories were represented. The $t$ tests reported in the text are based on these data.

Discrimination. Figure 4 shows the pooled discrimination functions for all nine subjects. Each function shows the percent correct discrimination for each comparison pair. One-step functions are shown in the upper part of the figure; two-step functions are shown below. ${ }^{5}$ The major result can best be seen in the one-step functions. The relatively more accurate discrimination of Comparison Pair 3-4 in both syl-
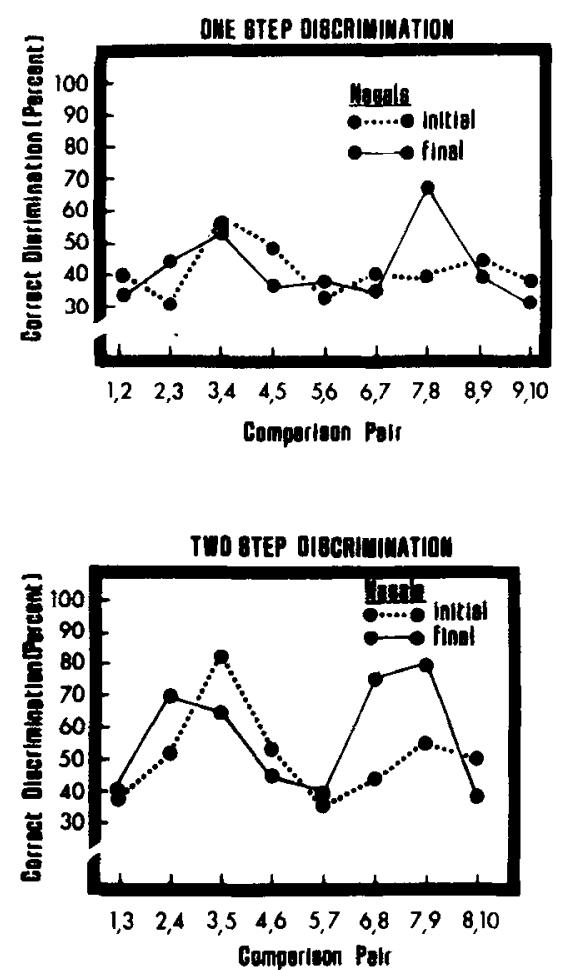

Figure 4. Pooled discrimination of one-step (upper) and twostep (lower) nasals: Experiment 1. lable conditions is consistent with the fact that the $/ \mathrm{m} /-\mathrm{n} / \mathrm{b}$ boundary fell between these stimuli for both the syilable-initial and the syllable-final nasals. Similarly, there is a relatively high level of discrimination for Comparison Pair 7-8, the stimulus pair that straddles the /æn/-/æy/ boundary on the syllable-final discrimination function. However, in the syllable-initial function, no discrimination peak appears for Pair 8-9, the stimuli bordering the /na/$/ \eta \mathfrak{a} /$ boundary. In fact, the level of discrimination is comparable to that observed for within-category pairs. In contrast to the level of discrimination obtained for the stimulus pairs that crossed familiar phoneme boundaries, most pairs of stimuli drawn from within phoneme categories were discriminated less well. This is reflected in the discrimination functions as "troughs" within the identification categories.

Examination of the two-step functions reinforces the one-step data. There is good discrimination of Pair 3-5, one of the pairs that straddles the $/ \mathrm{m} /$ $/ \mathrm{n} /$ boundary, for both syllable-initial and syllablefinal functions. Pair 2-4 in the syllable-final condition, which also straddles the boundary, was also discriminated relatively well. This contrasts with the poorer discrimination for most pairs lying completely within each of these categories. There is also a high level of discrimination for the syllable-final pairs 6-8 and $7-9$, the pairs that straddle the $/ \mathfrak{a n} /-/ \mathfrak{a}$ / boundary. This same level is not observed for the corresponding stimulus pairs on the syllable-initial function. The level of accuracy for these pairs is more like within-category discrimination. In short, discrimination performance at category boundaries is good except for the boundary that is not phonemic in English.

If, as these pooled functions suggest, familiarity with phonetic contrasts in specific syllabic contexts influences perception, individual subjects would be expected to show better discrimination for syllablefinal pairs than for syllable-initial pairs at their $/ \mathrm{n} /$ $/ y /$ boundaries. In order to test this hypothesis directly, one-tailed Wilcoxon signed-ranks tests for matched pairs (Mendenhall \& Ramey, 1973) were carried out on the one-step and two-step discrimination functions. First, each subject's syllable-initial and syllable-final $/ \mathrm{m} /-/ \mathrm{n} /$ and $/ \mathrm{n} /-/ \eta /$ boundaries were established from their identification performance. (If a particular boundary did not appear on a subject's identification function, the subject was excluded from the test performed for that boundary.) Then the number of correct judgments on syllableinitial and syllable-final discrimination tests were compared separately for the one- and two-step pairs that straddled that subject's boundaries. For onestep discrimination, only one stimulus pair was compared at each boundary. For two-step tests, the two stimulus pairs that straddled each boundary were 
considered; the sum of correct judgments for the two pairs was the score used in the statistical test.

The results of the Wilcoxon tests support the hypothesis that linguistic familiarity influences discriminability. Based on the data from six subjects on onestep tests, syllable-final nasals were better discriminated than syllable-initial nasals at the $/ \mathrm{n} /-/ \mathrm{n} /$ boundary by five of the subjects, a significant difference ( $p=.05$ by a one-tailed test). Five of the six subjects also showed better performance on the syllable-final nasals for two-step tests; however, this difference was not statistically significant considering the magnitude of the signed ranks.

No advantage of syllable-final stimuli was found for discrimination of the one-step and two-step pairs straddling the $/ \mathrm{m} /-/ \mathrm{n} /$ boundary. For the one-step functions, six out of seven subjects discriminated the syllable-initial $/ \mathrm{m} æ /-/ \mathrm{n} æ /$ pair better than they did the syllable-final $/ æ m /-/ æ n /$ pair. This is a large difference, but in the direction opposite that assumed by the one-tailed test, and thus cannot be considered significant. (By a two-tailed test, which does not assume a directional prediction, this difference would not be significant.) For the two-step functions, only three of eight subjects discriminated syllablefinal $/ \mathrm{m} /-/ \mathrm{n} /$ pairs better than their syllable-initial equivalents. Thus, as indicated by the pooled data, performance by individual subjects revealed relatively better discrimination of the $/ n /-/ \eta /$ contrast in the familiar and phonologically appropriate syllablefinal context. No such differences were found for the $/ \mathrm{m} /-\mathrm{n} / \mathrm{contrast}$, which is phonologically appropriate in both syllable positions.

Categorical perception. Two aspects of performance that reflect discontinuities in the perception of speech-relevant acoustic dimensions have been considered: (1) the steepness of the ascending and descending portions of the identification curves (which is an indication of the relative distinctiveness of stimuli at category boundaries) and (2) the relative discriminability of cross-category and intracategory equal-interval stimulus pairs. These kinds of discontinuity give evidence that the acoustic dimensions are perceived categorically. According to the strong claim of categorical perception, stimuli lying within one phoneme category (i.e., identified as the same phoneme) cannot be discriminated, while stimulus pairs containing tokens from different phoneme categories are easily discriminated. This claim may be tested directly by comparing the discrimination performance that is predicted on the basis of identification data with the discrimination functions that were actually obtained. ${ }^{6}$

Figure 5 shows the pooled predicted and obtained discrimination functions for the syllable-initial and syllable-final nasals. Both one-step and two-step functions are shown. Although the obtained discrim-
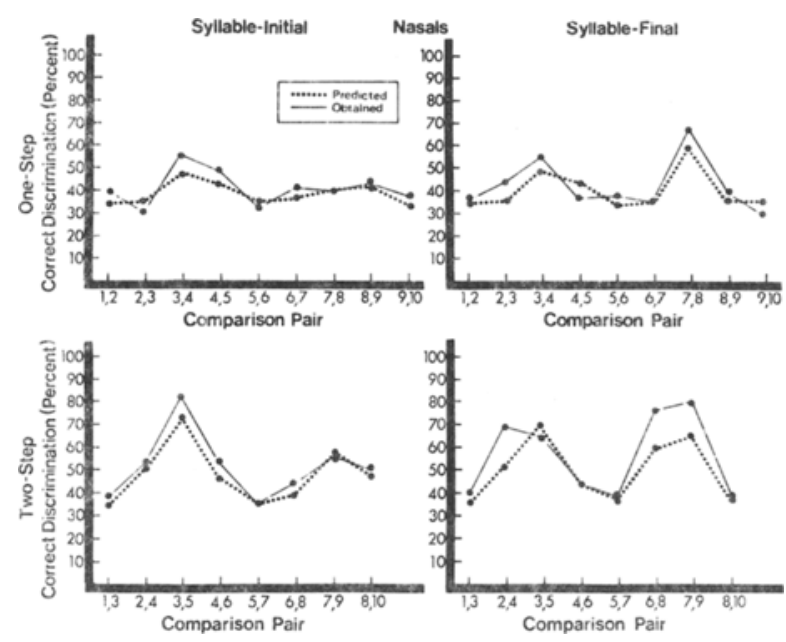

Figure 5. Predicted (dotted) and obtained (solid) pooled discrimination functions for one-step (upper) and two-step (Jower) nasals. Syllable-initial comparisons are on the left; syllable-final comparisons are on the right: Experiment 1.

ination scores are typically higher than the predicted scores, especially for the syllable-final condition, the location of the peaks of relatively accurate discrimination for the predicted and obtained functions correspond to one another quite closely. Chi-square tests of goodness of fit were calculated for each subject's predicted and obtained one-step and two-step discrimination functions in each syllable condition. In no case were the predicted and obtained discrimination functions significantly different from one another. ${ }^{7}$ Thus, each subject's discrimination of stimulus pairs was conditioned by the way the subject labeled those pairs; that is, each subject perceived the nasals in a categorical manner.

The results of this experiment provide initial answers to the three questions presented in the introduction. First, the synthetic stimuli were identified quite reliably as tokens of the intended phoneme classes. Second, the acoustic dimension that differentiates place-of-articulation in both syllable-initial and syllable-final nasals was shown to be perceived categorically. This is in accord with results of experiments on consonants of other manner classes in which place-of-articulation was distinguished by similar acoustic parameters (Mattingly et al., 1971; McGovern \& Strange, 1977; Miyawaki et al., 1975), and with the results reported by Miller and Eimas (1977) on the $/ \mathrm{m} /-/ \mathrm{n} /$ distinction. As in these studies, the present experiment yields a distinctive pattern of results. Identification tests yielded consistent labeling functions with abrupt crossovers from category to category; discrimination of stimulus pairs showed the "peaks" and "troughs" that are predictable on the basis of identification results for each subject. 
Finally, comparisons of syllable-initial and (mirrorimage) syllable-final nasals suggested an effect on perception of the "hole in the code" produced by the phonological rules of English. Average functions showed relatively accurate discrimination (and consistent identification) of stimuli in the region of the $/ \mathrm{n} /-/ \mathrm{g} /$ boundary for the syllable-final condition where this phonetic contrast is phonologically appropriate and therefore familiar to the listeners. However, for stimuli that marked the same phonetic contrast in syllable-initial position (where it does not occur in English), discrimination was little better than for within-category comparisons. Identification performance also gave some suggestion that the syllable-initial $/ \eta /$ phoneme category was less well defined perceptually than the familiar syllable-final $/ y /$.

\section{EXPERIMENT 2}

In the previous experiment, the results of identification and discrimination of stimuli in the region of the $/ \mathrm{m} /-/ \mathrm{n} /$ boundary-a contrast that is phonemic in both syllabic positions - were used as evidence that the perception of syllable-initial and syllable-final place contrasts is comparable if the contrasts are phonologically appropriate in both contexts. On the assumption that there were no complex interactions between the "intrinsic" discriminability of initial and final transitions and the particular acoustic differences that underlie the two phonetic contrasts, we could conclude that the differences in performance on the $/ \mathrm{n} /-/ \mathrm{\eta} /$ boundary stimuli were due to phonological factors. One may question the assumption upon which this conclusion is based, however; we have no independent way of ascertaining its validity in the previous experiment. Indeed, the unexpected advantage of syllable-initial $/ \mathrm{m} /-/ \mathrm{n} /$ discrimination casts doubt on this as an appropriate control. One way to avoid this ambiguity is to include series of syllable-initial and syllable-final consonants that are acoustically comparable to the nasals, but that include an alveolar-velar phonetic contrast that is phonologically appropriate in both syllabic contexts.

Experiment 2 was designed as a replication of Experiment 1 with the addition of this control. Two series of tests were included that used the oral stop consonant stimuli, $/ \mathrm{b} /, / \mathrm{d} /$, and $/ \mathrm{g} /$, in syllableinitial and syllable-final position. We expected that the identification and discrimination of these stimuli would not differ as a function of syllable position in the same way that the nasals did, since there is no "hole" in the phonetic code for oral stop consonants. That is, all three phonemes occur in both syllableinitial and syllable-final position in English.

\section{Method}

Stimulus materials. The nasal stimuli were the same as those described in Experiment 1. The (syllable-initial) stop stimuli were a series of 10 three-formant stop $+/ \mathbf{a} /$ syllables which were the same as the nasal stimuli except for the following: (1) the nasal formant was deleted, (2) the first oral formant began simultaneously with the upper formants at a center frequency of $200 \mathrm{~Hz}$ and rose in a linear transition to its steady-state value in $40 \mathrm{msec}$, and (3) the onset of all three formants was abrupt. The transitions of F2 and F3 for the 10 stop stimuli were identical in frequency and amplitude to those transitions in the nasal stimuli, as depicted in Figure 1. Thus, the variable portions of the stimuli were exactly the same for the stops and the nasals.

The sequencing of stimuli for the familiarization, identification, and discrimination tests were identical for both the stop and nasal tests. As before, tests of the syllable-final stops were presented by reversing the tape recordings of the syllable-initial stops.

Subjects. Sixteen undergraduates at the University of Minnesota were either paid for their participation in the experiment or received a combination of money and extra credit toward a grade. All were native English speakers with no known hearing losses. Prior to familiarization, subjects were told only that the experiment was concerned with how well people could perceive synthesized syllables.

Procedure. The 16 subjects were tested in four groups of 4; each group was tested on 4 consecutive days. The first and third groups were tested on syllable-final nasals on the 1st day, syllableinitial nasals on the 2nd day, syllable-final stops on the 3 rd day, and syllable-initial stops on the 4 th day. The second and fourth groups were tested on the series in the order: syllable-final stops, syllable-initial stops, syllable-final nasals, syllable-initial nasals. Thus, subjects always heard syllable-final consonants before syllable-initial consonants in each consonant condition, as in Experiment 1, but the order of presentation of stops and nasals was counterbalanced.

Each day, the subjects first listened to the appropriate familiarization series and reported what they had heard. They were then informed of the phonetic identity of the syllables and were asked to listen for those syllables while they heard the recording for a second time. They were allowed to listen to the familiarization recording repeatedly until they said they could hear all three phonemes; this took from two to five repetitions. (At this point, some of the subjects reported that identification of the syllables was still very difficult.)

Following the familiarization period, the subjects were tested on the first identification test, then the first discrimination subtest, and finally the second discrimination subtest. After a 5 -min break, the subjects performed a similar series of tests using the second identification test, the second discrimination subtest, and finally the first discrimination subtest.

The first session usually lasted approximately $1 \frac{1}{2} \mathrm{~h}$; the other sessions were about $1 \mathrm{~h}$ in length. The sequence of familiarization, identification, and discrimination testing was the same on each successive day of testing. In each experimental condition, the subjects listened to each of the identification tests and to each of the discrimination subtests twice, giving a total of 20 identification judgments per stimulus and 12 discrimination judgments per comparison pair. ${ }^{8}$

\section{Results and Discussion}

In this section, identification and discrimination of nasals are considered first; then the results for the oral stop consonants are reported. In general, the results for the nasal stimuli replicate those of the first experiment. In particular, nasals were categorically perceived, and syllable-final $/ \mathrm{n} /$ and $/ \mathrm{g} /$ were identified more consistently and discriminated better than 
were syllable-initial $/ \mathrm{n} /$ and $/ \mathrm{\eta} /$. The stop consonants, in contrast, did not yield differences in the perception of the syllable-initial and syllable-final tokens.

Familiarization. Some subjects sporitaneously reported hearing all three nasal phonemes when the familiarization series was first presented. Most reported hearing all three phonemes when the recording was again presented after telling the subjects what phonemes they should hear. The few subjects who still had difficulty at the end of the familiarization trials claimed that by the end of the first identification test they heard all phonemes without difficulty.

Identification of nasal consonants. Figure 6 shows the pooled identification functions for all 16 subjects. In general, the subjects were able to label the stimuli consistently in both syllable positions, although performance was slightly better on syllable-final nasals. A closer examination of category boundaries sheds some light on the nature of the difference between identification of initial and final nasals. As in Experiment 1 , the pooled boundary between $/ \mathrm{m} /$ and $/ \mathrm{n} /$ occurred between Stimuli 3 and 4, with little difference between syllable-initial and syllable-final nasals. In contrast, the pooled boundary between $/ \mathrm{n} /$ and $/ \eta /$ for syllable-initial nasals is shifted to the right relative to syllable-final stimuli. As mentioned previously, this rightward shift of the /næa/-/næa/ boundary shows a tendency to call fewer stimuli $/ \mathrm{n} /$ in the syllable-initial condition than in the syllablefinal condition. (However, the shift is not as large as the comparable shift noted in Experiment 1.)

Figure 7, which presents the distribution of category boundaries, indicates how individual subjects contributed to the pooled boundary shift. Note that for syllable-final nasals, 10 of the 16 subjects showed $/ \mathfrak{n} /-/ \mathfrak{m} /$ boundaries at the modal value, between Stimuli 7 and 8 . Boundaries for the other 6 subjects fell within one (full) stimulus step of this modal value. For syllable-initial nasals, however, the /na/$/ \eta \mathfrak{x} /$ boundaries for only 6 subjects occurred at the modal value between Stimuli 7 and 8 . Of the remaining 10 subjects, 7 produced boundaries within one
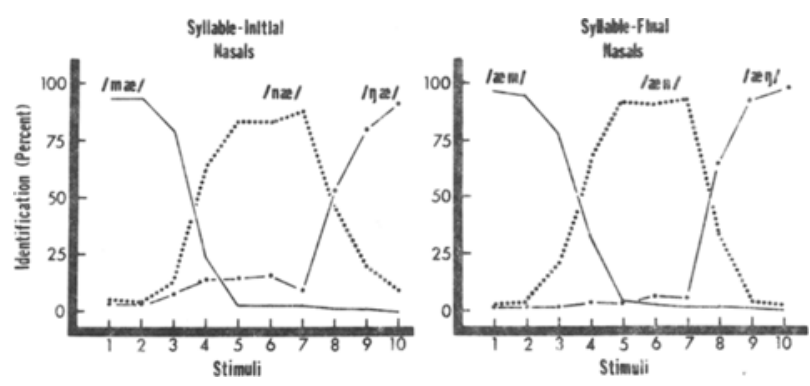

Figure 6. Pooled identification of syllable-initial (left) and syllable-final (right) nasals: Experiment 2.
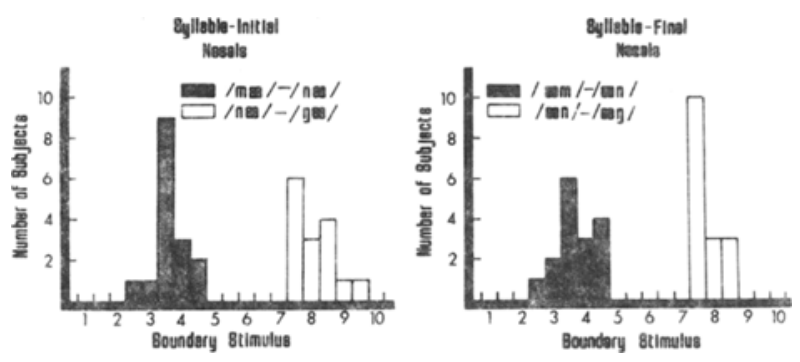

Figure 7. Frequency histogram of subjects' category boundary locations for nasals: Experiment 2.

step of the mode, but 2 subjects produced boundaries farther to the right than any subjects had in the syllable-final tests, and 1 subject produced no clear boundary at all.

Two other differences are apparent upon comparing the two identification functions in Figure 6. First, the boundary between /æn/ and /æy/ (on the right) is somewhat steeper than the boundary between /na/ and $/ \mathrm{g} /$ (on the left). Secondly, although the identification functions for $/ \mathrm{mæ} /$ and $/ æ m /$ are about the same, /næ/ and $/ \eta \mathfrak{m} /$ are identified less consistently than /æn/ and /æy/; that is, more stimuli in the /næ/ category are called / $\mathbf{g} \mathbf{a} /$, and vice versa.

The functions of individual subjects are similar to the pooled functions: A measure of consistency of identification for each of the three categories in each syllabic position was calculated, using the same procedure as in Experiment 1 (described in the Appendix). Table 2 presents each subject's consistency scores and average consistency scores for each category in syllable-initial and syllable-final conditions. A correlated $t$ test shows no significant difference in consistency of identifying tokens of $/ \mathfrak{a m} /$ and $/ \mathrm{mæ} /$. In contrast, consistency of identification within the $/ æ \eta /$ category is significantly greater than within the / $\mathfrak{a x} /$ category $(\mathrm{p}<.03)$, and consistency of /æn/ identification is significantly greater than consistency of / na/ identification $(\mathrm{p}<.05)$. The latter finding seems to be due to confusion in distinguishing /næ/ from / $/ \mathfrak{a} /$, which would lead to more incorrect labeling of stimuli in both categories. Thus, these results are in accord with expectations based on the phonemic use of these sounds in English.

Discrimination of nasal consonants. Figure $8 \mathrm{com}$ pares the pooled discrimination of syllable-initial nasals with syllable-final nasals. One-step and twostep functions are shown in the upper and lower portions of the figure, respectively. The major result of interest is best seen in the one-step discrimination functions. There is a large discrimination peak in the syllable-final function for Comparison Pair 7-8, which corresponds to the modal /æn/-/æy/ boundary, while there is no peak at the corresponding $/ \mathrm{n} \mathfrak{} /-/ \eta \mathfrak{r} /$ boundary in the syllable-initial function. 
Table 2

Consistency Scores: Experiment 2

\begin{tabular}{|c|c|c|c|c|c|c|}
\hline & \multicolumn{3}{|c|}{$\begin{array}{l}\text { Syllable-Initial } \\
\text { Nasals }\end{array}$} & \multicolumn{3}{|c|}{$\begin{array}{l}\text { Syllable-Final } \\
\text { Nasals }\end{array}$} \\
\hline & mae & nae & gae & $æ m$ & aen & ae \\
\hline Subject 1 & .68 & .56 & .41 & .95 & .93 & 1.00 \\
\hline Subject 2 & .90 & .93 & .95 & .90 & .70 & .71 \\
\hline Subject 3 & .91 & .80 & .85 & .75 & .75 & .85 \\
\hline Subject 4 & .56 & .61 & .28 & .63 & .55 & .77 \\
\hline Subject 5 & .80 & .66 & .83 & .97 & .94 & 1.00 \\
\hline Subject 6 & .83 & .85 & .98 & .83 & .80 & .93 \\
\hline Subject $?$ & .78 & .86 & .93 & .80 & .81 & .87 \\
\hline Subject 8 & .85 & .68 & .78 & .90 & .84 & .92 \\
\hline Subject 9 & .83 & .66 & .83 & .96 & 1.00 & 1.00 \\
\hline Subject 10 & .83 & .57 & .51 & .87 & .94 & .93 \\
\hline Subject 11 & .98 & .70 & .43 & .98 & .89 & .93 \\
\hline Subject 12 & .98 & .72 & .85 & .85 & .80 & .83 \\
\hline Subject 13 & .89 & .83 & .65 & .86 & .89 & .97 \\
\hline Subject 14 & .73 & .96 & .97 & .93 & .88 & .83 \\
\hline Subject 15 & .84 & .85 & .90 & .85 & .78 & .80 \\
\hline Subject 16 & .97 & .73 & .93 & .88 & .87 & 1.00 \\
\hline Mean & .83 & .75 & .76 & .87 & .83 & .90 \\
\hline
\end{tabular}

The small discrimination peaks at Comparison Pair $3-4$, which correspond to the modal $/ \mathrm{m} /-/ \mathrm{n} /$ boundaries, are comparable for syllable conditions. Discrimination within phoneme categories is, on the average, relatively poor in both conditions.

Turning to the two-step functions, it is relevant to compare performance on two discrimination pairs at each boundary. Pairs 6-8 and 7-9 both span the modal $/ \mathrm{n} /-/ \mathrm{\eta} /$ boundary, in each syllable condition. For Pair 6-8, final nasals are discriminated much better on the average than are initial nasals. For Pair 7-9, final nasals are again discriminated better than initial nasals, although the magnitude of the difference is smaller. In contrast, at the $/ \mathrm{m} /-/ \mathrm{n} /$ boundary, there is almost no difference in average performance between initial and final nasals for Pair 2-4 and a small difference favoring final nasals for Pair 3-5. Average discrimination of pairs within a phoneme category is less accurate than for pairs spanning phoneme boundaries.

A similar pattern of results was found when we compared individual subjects' discriminations in the two syllabic positions. In each condition, each subject's boundaries were determined from his identification functions, as in Experiment 1. Wilcoxon tests were performed to determine whether discrimination was significantly better at syllable-final boundaries than at syllable-initial boundaries. For two-step functions, the Wilcoxon test was based on the summed correct judgments of the two relevant boundary pairs. Both one-step and two-step comparisons at the $/ \mathrm{n} /-\mathrm{g} /$ boundary showed significantly better discrimination of syllable-final nasals $(p=.005$ and $\mathrm{p}=.025$, respectively, by a one-tailed test). Contrary to expectation, syllable-final nasals were also discriminated better than syllable-initial nasals at the $/ \mathrm{m} /-\mathrm{n} / \mathrm{boundary}(\mathrm{p}=.025$ ) for the two-step test. No such difference was found for the one-step comparisons: however. These results support the hypothesis that discriminability is determined, at least in part, by linguistic experience.

Categorical perception of nasal consonants. Figure 9 compares the pooled obtained and predicted discrimination functions, computed as described in Footnote 5 . An inspection of the figure shows that functions for syllable-initial nasals match the predictions better than do syllable-final functions. For the latter, the obtained scores were slightly higher than was predicted, both for comparison pairs within categories and across category boundaries.

Chi-square tests of goodness of fit calculated separately for each subject's one-step and two-step functions showed that, for syllable-final nasals, only 2 out of 16 subjects yielded significant differences between predicted and obtained functions. For syllable-initial nasals, there were no significant differences between predicted and obtained performance. (But see Footnote 6.) Thus, performance on the labeling task predicts discrimination quite well; that is, perception of nasals is categorical for almost all of the subjects.

Identification and discrimination of stop consonants. Considering the nasals alone, our results have
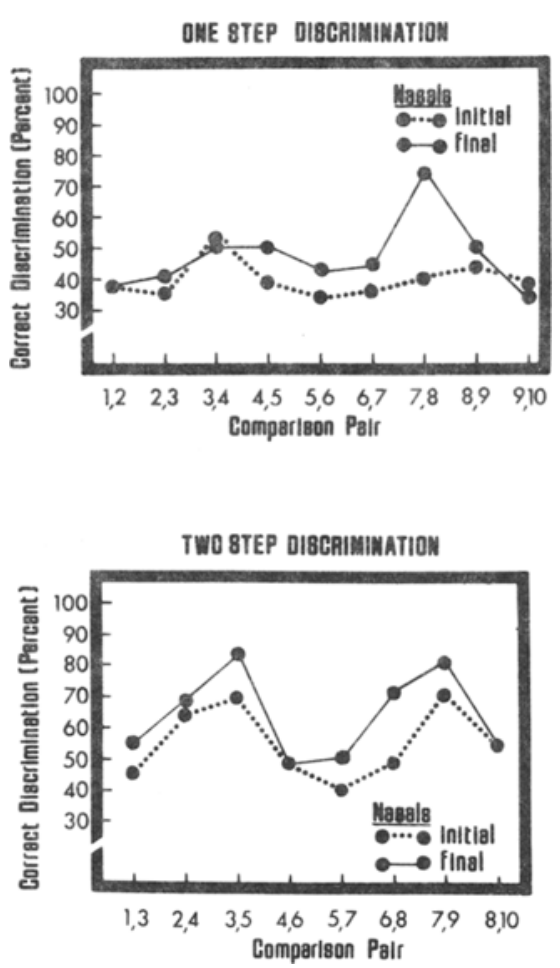

Figure 8. Pooled discrimination of one-step (upper) and twostep (lower) nasals: Experiment 2. 

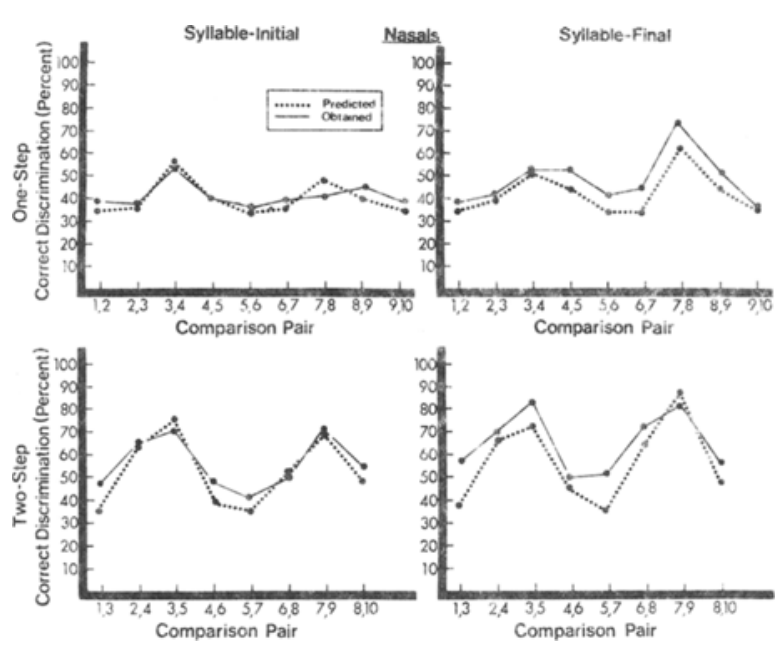

Figure 9. Predicted (dotted) and obtained (solid) pooled discrimination functions for one-step (upper) and two-step (lower) nasals. Syllable-initial comparisons are on the left; syllable-final comparisons are on the right: Experiment 2.

shown that both initial and final nasal consonants are perceived categorically, and more important, these results have demonstrated an effect of the "hole in the code" on both identification and discrimination of these stimuli. Syllable-initial $/ \mathrm{n} /$ and $/ \mathrm{g} /$ were not as consistently identified nor as well discriminated as they were in syllable-final position.

In the preceding discussion, discrimination at the $/ \mathrm{m} /-\mathrm{n} /$ boundary served as a control for discrimination at the $/ \mathrm{n} /-/ \mathrm{\eta} /$ boundary. That is, since both initial and final $/ \mathrm{m} /$ and $/ \mathrm{n} /$ occur in English, we expected no difference in discriminability at the $/ \mathrm{m} /-/ \mathrm{n} /$ boundary due to syllable position. However, as noted above, significant differences were found for the two-step functions.

As an additional control, we compared the pattern of discrimination of the nasal series with the pattern of discrimination of the comparable series of the oral stop consonants. We expected that, in contrast with the nasals, the stops would fail to show the differential effect of syllable position in the way that the nasals did, since there is no "hole in the code" for stops. Thus, we predicted that the syllable-final $/ \mathrm{d} /-$ $/ \mathrm{g} /$ contrast would not be identified more consistently or be better discriminated than the $/ \mathrm{d} /-\mathrm{g} /$ contrast in initial stops. If there were any advantage due to syllable position, we expected that it might be in favor of the syllable-initial stops, as the results of Mattingly et al. (1971) showed.

Figure 10 shows the pooled stop consonant identification functions for all 16 subjects. A comparison of Figure 10 with Figure 6 shows that, on the average, the stops are not identified as consistently as the nasals.
Comparison of the two graphs in Figure 10 suggests that the final stops were better perceived than the initial stops. Two points can be noted about this difference, however. First, consideration of the part of the functions that is of interest in this experiment (Stimuli 7 through 9 that have to do with the boundary between $/ \mathrm{d} /$ and $/ \mathrm{g} /$ shows that syllable-initial and syllable-final functions for the stops are virtually identical.

Secondly, the identification functions for syllableinitial and syllable-final stops appear different only at Stimuli 5 and 6. To a large extent, this difference is a property of the pooled functions. Identification functions for most individual subjects do not resemble the pooled function at Stimuli 5-6. As Figure 11 shows, there is considerable variability in the location of the $/ b /-/ d /$ boundary across individual subjects, yielding a bimodal distribution for syllableinitial stops. As a comparison of Figure 11 with Figure 7 shows, the distribution of $/ b /-/ d /$ category boundaries differs greatly from the distribution of $/ \mathrm{m} /-\mathrm{n} /$ boundaries. We currently have no explanation for these results.

The consistency scores in Table 3 support the interpretation that the apparent difference is due to variability in subjects' boundary locations. A correlated $\mathrm{t}$ test yielded no significant differences between consistency of identification of initial and final stop consonants.
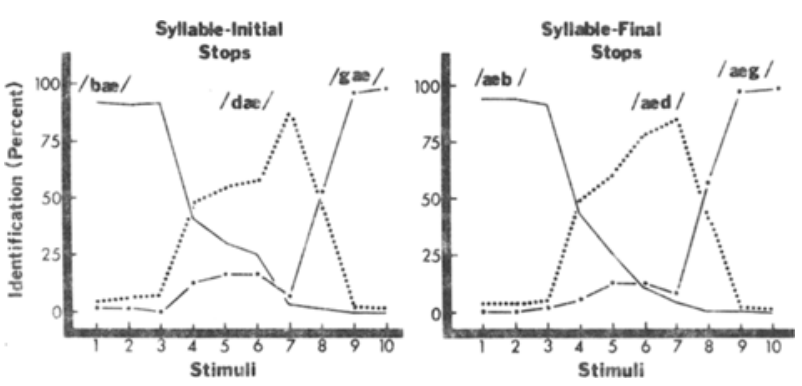

Figure 10. Pooled identification of syllable-initial (left) and syllable-final (right) stops: Experiment 2.
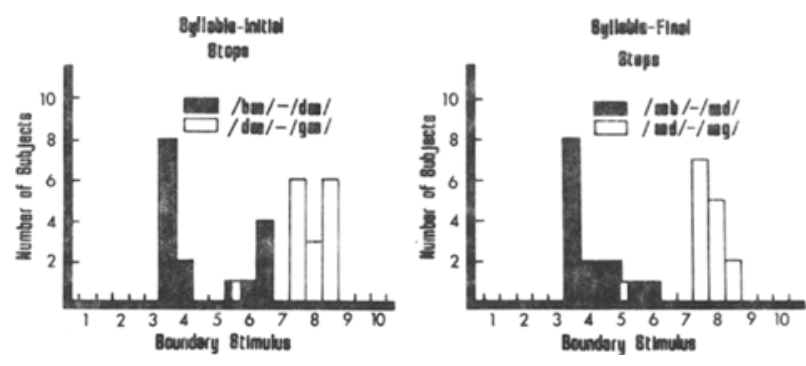

Figure 11. Frequency histogram of subjects'. category boundary locations for stops: Experiment 2. 
Table 3

Consistency Scores: Experiment 2

\begin{tabular}{|c|c|c|c|c|c|c|}
\hline & \multicolumn{3}{|c|}{$\begin{array}{l}\text { Syllable-Initial } \\
\text { Stops }\end{array}$} & \multicolumn{3}{|c|}{$\begin{array}{c}\text { Syllable-Final } \\
\text { Stops }\end{array}$} \\
\hline & bae & dae & gae & aeb & aed & aeg \\
\hline Subject 1 & .80 & 69 & .88 & .98 & .90 & 1.00 \\
\hline Subject 2 & .90 & .58 & .66 & .98 & .42 & .72 \\
\hline Subject 3 & .90 & .85 & 1.00 & .85 & .83 & .93 \\
\hline Subject 4 & .90 & .98 & .98 & .73 & .52 & .69 \\
\hline Subject 5 & .85 & .69 & .49 & .72 & .48 & .90 \\
\hline Subject 6 & .75 & .60 & .73 & .95 & .75 & .82 \\
\hline Subject 7 & .87 & .82 & .80 & .71 & .77 & .90 \\
\hline Subject 8 & .70 & .62 & .78 & .87 & .73 & .87 \\
\hline Subject 9 & 1.00 & .64 & .57 & .98 & .82 & 1.00 \\
\hline Subject 10 & .72 & .45 & .61 & 1.00 & .84 & .82 \\
\hline Subject 11 & .95 & .72 & .52 & .93 & .49 & .54 \\
\hline Subject 12 & .98 & .93 & .92 & .82 & .85 & .98 \\
\hline Subject 13 & .88 & .65 & .88 & 1.00 & .90 & .98 \\
\hline Subject 14 & .79 & .55 & .73 & 1.00 & .86 & .87 \\
\hline Subject 15 & .98 & .87 & 1.00 & .90 & .83 & .80 \\
\hline Subject 16 & .85 & .84 & .97 & .50 & .72 & .92 \\
\hline Mean & .86 & .72 & .80 & .87 & .73 & .86 \\
\hline
\end{tabular}

Discrimination of stop consonants. Figure 12 compares the pooled discrimination of syllable-initial stops with the pooled discrimination of syllable-final stops. Results for both one-step and two-step discrimination functions were in keeping with the expectation that syllable-final stops would not be superior to syllable-initial stops. As seen in the bottom portion of the figure, the two-step functions for syllable-
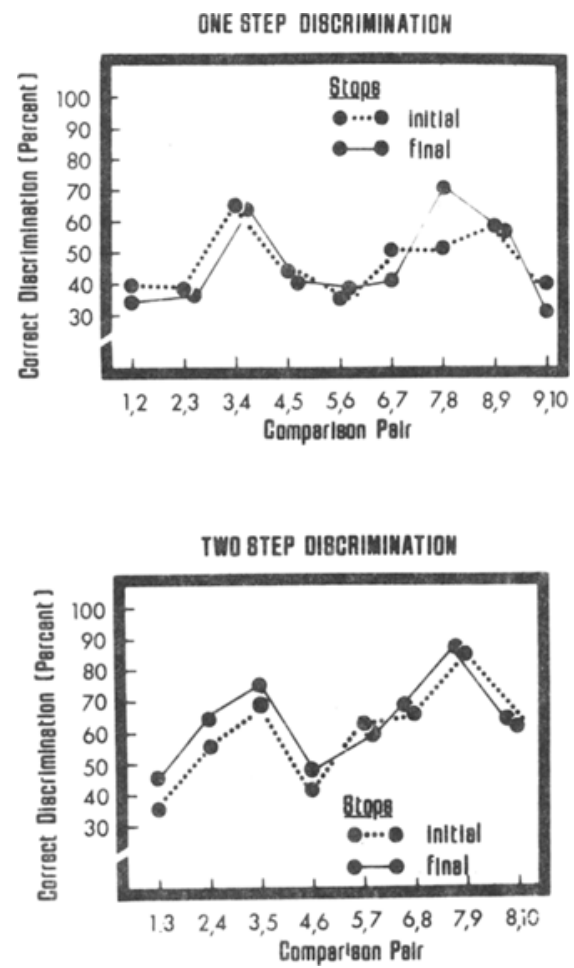

Figure 12. Pooled discriminalion of one-step (upper) and two. step (lower) stops: Experiment 2. initial stops and syllable-final stops did not differ. The one-step functions in the upper portion show an apparent syllable-position effect for Pair 7-8. However, Wilcoxon tests comparing performance on pairs at each subject's boundary yielded no significant differences either in one-step or two-step discrimination.

A summary of the comparison between nasal and stop consonants is given in Table 4. We conclude that the syllable-position effect found for the perception of nasal consonants supports the "hole in the code"' hypothesis. The evidence for this is as follows: (1) Identification consistency showed a syllableposition effect for the $/ \mathrm{n} /$ and $/ \mathrm{g} /$ nasal categories, but not for the comparable stops $/ \mathrm{d} /$ and $/ \mathrm{g} /$. (2) Discrimination performance showed a syllableposition effect for nasals at the $/ \mathrm{n} /-/ \mathrm{g} /$ boundary but not for stops at the $/ d /-/ g /$ boundary. (3) No

Table 4

Summary of Results: Experiment 2

\begin{tabular}{|c|c|c|c|c|c|}
\hline & \multicolumn{3}{|c|}{ Consistency of Identification } & \multicolumn{2}{|c|}{ Discrimination } \\
\hline & $\mathrm{m}$ & $\mathrm{n}$ & $\eta$ & $m-n$ & $n-\eta$ \\
\hline Nasals & $=$ & final $>$ initial & final $>$ initial & $(=)$ & final $>$ initial \\
\hline Stops & $=$ & $=$ & $=$ & $=$ & $=$ \\
\hline & $b$ & $d$ & $g$ & $b-d$ & $d-g$ \\
\hline
\end{tabular}

Note- " =" indicates no significant difference between final and initial positions; " $=)$ " indicates no consistent difference between final and initial positions-differed on two-step tests but not on one-step tests.

consistent syllable-position effects were found either in identification of labial phonemes $(/ \mathrm{m} /$ and $/ \mathrm{b} /)$ or in discrimination at the labial-alveolar boundaries $(/ \mathrm{m} /-/ \mathrm{n} /$ and $/ \mathrm{b} /-/ \mathrm{d} /)$.

\section{GENERAL DISCUSSION}

In the experiments reported above, we were interested in two major questions concerning the perception of nasal consonants. First, was the place-of articulation of nasals, as cued by $\mathrm{F} 2 / \mathrm{F} 3$ transitions, perceived categorically? Second, was the perception of particular phonetic contrasts affected by linguistic usage? Specifically, was discrimination of the alveolarvelar contrast in syllable-initial nasals (where it is phonologically inappropriate) less accurate than for the same contrast in syllable-final nasals, where it is phonologically appropriate and familiar to the listeners?

Previous research by Garcia (Notes 1 and 2) concerning the categorical perception of nasals prodiced ambiguous results on the $/ \mathrm{n} /-/ \mathrm{y} /$ distinction due to the fact that the stimuli were not identifiabl: as "good" instances of the phonemes in question. The 
results reported here have shown that it is possible to synthesize highly identifiable instances of nasal stop consonants in both syllable-initial and syllablefinal position by varying only the direction and extent of the second and third oral formants. While these "cues" for place-of-articulation are not the only ones that occur in naturally produced nasals (Fujimura, 1962; Malécot, 1956), the results of both familiarization and identification tests indicate that the transition variations provided sufficient information for most listeners to identify the consonants unambiguously.

Comparison of identification and discrimination tests of both syllable-initial and syllable-final nasals showed that the F2/F3 acoustic dimension was perceived categorically. Subjects were able to discriminate with high accuracy only those acoustic variations that differentiated phonemes in English. Acoustic differences of the same magnitude that were linguistically irrelevant (i.e., did not mark a phonemic contrast) were discriminated considerably less accurately. This is in accord with the results obtained by Miller and Eimas (1977) for stimuli that contrasted the labial and alveolar nasal consonants in syllable-initial and syllable-final position.

Of major interest was the finding of a syllableposition effect in discrimination (and to a lesser extent, identification) of stimuli in the region of the $/ \mathrm{n} /-/ \mathrm{g} /$ phoneme boundary. As expected on the basis of English usage, identification of these tokens was somewhat less consistent for syllable-initial nasals than for syllable-final nasals. More importantly, discrimination of pairs that straddled this phoneme boundary was different in the two syllabic conditions. That is, discrimination of the acoustic variations that differentiate $/ \mathbf{n} /$ from $/ \eta /$ in syllableinitial position was poorer than discrimination of the mirror-image patterns that differentiated those phonemes in syllable-final position. This is probably not due to "intrinsic" differences in the discriminability of initial transitions vs. final transitions. We found no consistent discrepancies for stimuli that differentiated $/ \mathrm{m} /$ and $/ \mathrm{n} /$ in syllable-initial and syllable-final position (although, in Experiment 2, two-step functions did show a difference). Furthermore, an examination of oral stop consonants, which were also differentiated only by $F 2 / F 3$ variations, showed that discrimination of syllable-initial and syllable-final stimuli did not differ. A direct comparison of initial oral and nasal stops showed that when the F2/F3 variations cued the $/ \mathrm{n} /-/ \mathrm{g} /$ contrast, they were discriminated far less accurately than when the same variations cued the $/ \mathrm{d} /-/ \mathrm{g} /$ contrast. No such difference between oral and nasal stops was found for the mirror-image $F 2 / F 3$ variations in syllable-final transitions. We concluded from this configuration of results that the differences in discrimination of stim- uli that contrast $/ \mathrm{n} /$ and $/ \mathrm{g} /$ in initial and final syllabic position were due, at least in part, to linguistic experience. Subjects' ability to perceive a phonetic contrast was influenced by their familiarity with that contrast in the particular syllabic contexts in which it occurred. They were able to discriminate the acoustic variations with high accuracy only if those variations provided information for a phonetic contrast in a syllabic context that was appropriate according to the phonological rules of English.

This result is congruent with the findings from cross-language studies and the study reported by Abramson and Lisker (1970) with Thai speakers that was described in the introduction of this paper. Together, these data constitute strong evidence that the perception of acoustic dimensions that differentiate the phonemes of a language is influenced by the linguistic experience of the perceiver. Adult speakerhearers appear to be attuned to perceive only those acoustic variations that "make a difference" in terms of extracting the phonological message from the acoustic signal. (See Strange and Jenkins, in press, for a full review of the effects of linguistic experience on the categorical perception of speech.)

The fact that linguistic experience affects the (categorical) perception of some linguistically relevant acoustic dimensions is important in light of recent theoretical developments concerning an explanation of categorical perception phenomena. Studies showing that infants as young as 2 months of age discriminated linguistically relevant acoustic dimensions in a discontinuous manner similar to that of adults (e.g., Eimas, 1975a, 1975b) have led to the postulation of the existence of "property detectors" that underlie the perceptual processing of some acoustic dimensions (Eimas \& Corbit, 1973). Much recent research has been devoted to an investigation of the nature and functioning of these detector mechanisms, including their short-term modifiability (cf. Eimas \& Miller, in press, for a review). However, little theoretical or empirical effort has been directed towards the question of the long-term modifiability of the perceptual processes underlying categorical perception of speech-relevant dimensions. It is our opinion that an adequate account of categorical perception phenomena and, more generally, of the perception of speech must take into account these facts about the role of long-term linguistic experience in perception.

\section{APPENDIX A}

\section{Derivation of Consistency Scores}

Consistency scores were calculated in order to quantify subjects' performances on the identification task. For each subject within a condition, a consistency score was derived 
for the subject's identification of each phoneme category. For a given phoneme category, $j$, this score is the fraction:

(1) $C_{j}=$ the number of tokens in the subject's category $\mathrm{j}$, which was labeled $\mathrm{j} \div$ the total number of tokens in the subject's category $j$.

The following two steps were used to decide which stimuli were in a subject's category $\mathrm{j}$ :

(a) Stimulus $\mathrm{i}$ is in category $\mathrm{j}$ if the subject labels $\mathrm{i}$ as a $j$ more than $33 \%$ of the time in the identification task.

(b) If the stimuli in a category are not consecutive according to the criterion in Step a, the intervening stimuli should also be added to the category. (When this happens it lowers computed consistency. We believe this is reasonable because consistent categorization should include defining the category by consecutive stimuli.) Using the numbers 1 through 10 to label the stimuli as before, let $a_{j}$ be the lowest numbered stimulus in category $j$, let $b_{j}$ be the highest numbered stimulus in category $\mathrm{j}$, and let $\mathrm{P}_{\mathrm{ij}}$ be the proportion of stimulus $i$ tokens labeled $j$.

The equation in (1) then becomes:

$$
C_{j}=\frac{\sum_{i=a_{j}}^{b_{j}} P_{i j}}{\sum_{i=a_{j}}^{b_{j}} 1}=\frac{\sum_{i=a_{j}}^{b_{j}} P_{i j}}{1+b_{j}-a_{j}} .
$$

\section{REFERENCE NOTES}

1. Garcia, E. Discrimination of three-formant nasal-vowel syllables. (III) Haskins Laboratories Status Report on Speech Research, SR-12, 1967.

2. Garcia, E. Labeling of synthetic nasals. (II) Haskins Laboratories Status Report on Speech Research, SR-9, 1967.

\section{REFERENCES}

Abramson, A. S., \& Lisker, L. Discriminability along the voicing continuum: Cross-language tests. In Proceedings of the Sixth International Congress of Phonetic Science. Prague: Academia, 1970. Pp. 569-573.

Cutting, J., \& Rosner, B. S. Categories and boundaries in speech and music. Perception \& Psychophysics, 1974, 16, 564-570.

Delattre, P. C. Acoustic cues in speech: First report. Phonetica, 1958, 2, 108-118.

Eimas, P. D. Speech perception in early infancy. In L. B. Cohen \& P. Salapatek (Eds.), Infant perception. New York: Academic Press, 1975. (a)

Ermas, P. D. Auditory and phonetic coding of the cues for speech: Discrimination of the $[\mathrm{r}-1]$ distinction by young infants. Perception \& Psychophysics, 1975, 18, 341-347. (b)

Eimas, P. D., \& Cora IT, J. D. Selective adaptation of linguistic feature detectors. Cognitive Psychology, 1973, 4, 99-109.

Eimas, P. D., \& Miller, J. L. Effects of selective adaptation on the perception of speech and visual patterns: Evidence for feature detectors. In H. L. Pick, Jr., \& R. D. Walk (Eds.), Perception and experience. New York: Plenum, in press.

Fry, D. B., Abramson, A. S., Eimas, P. D., \& Liberman, A. M. The identification and discrimination of synthetic vowels. Language and Speech, 1962, 5, 171-189.
Fujimura, O. Analysis of nasal consonants. Journal of the Acoustical Society of A merica, 1962, 34, 1865-1875.

Harris, K. S., Hoffman, H. S., Liberman, A. M., Delattre, P. C., \& COOPER, F. S. Effect of third-formant transitions on the perception of the voiced stop consonants. Joumal of the Acoustical Society of A merica, 1958, 30, 122-126.

Liberman, A. M., CoOper, F. S., Shankweiler, D. P., \& Studdert-Kennedy, M. Perception of the speech code. Psychological Review, 1967, 74, 431-461.

liberman, A. M., Delattre, P. C., Cooper, F. S., \& Gerstman, L. J. The role of consonant-vowel transitions in the perception of the stop and nasal consonants. Psychological Monographs, 1954. 68(Whole No. 379).

LIBERMAN, A. M., HaRris, K. S., HOFfMaN, H. S., \& GRIFFITH, B. C. The discrimination of speech sounds within and across phoneme boundaries. Journal of Experimental Psychology, 1957, 54, 358-368.

Malécot, A. Acoustic cues for nasal consonants. Language, $1956,32,274.284$.

Matringly, I. G., Liberman, A. M., Syrdal, A. K., \& Halwes, T. Discrimination in speech and non-speech modes. Cognitive Psychology, 1971, 2, 131-157.

McGovern, K., \& Strange, W. Perception of $/ r /$ and $/ 1 /$ in syllable-initial and syllable-final position. Perception \& Psychophysics, 1977, 21, 162-170.

Mendenharl, W., \& Ramey, M. Statistics for psychology. North Scituate, Mass: Duxbury Press, 1973.

Miller, J. L., \& Eimas, P. D. Studies on the perception of place and manner of articulation: A comparison of the labialalveolar and nasal-stop distinctions. Journal of the Acoustical Society of America. 1977, 61, 835-845.

Miyawaki, K., Strange, W., Verbrugge, R. R., Liberman, A. M., JENKINS, J. J., \& Fummura, O. An effect of linguistic experience: The discrimination of [ $\mathrm{r}$ ] and [I] by native speakers of Japanese and English. Perception \& Psychophysics, 1975, 18, 331-340.

O'Connor, J. D., Gertsman, L. J., Liberman, A. M., Delattre, P. C., \& Cooper, F. S. Acoustic cues for the perception of initial /w, j, r, 1/ in English. Word, 1957, 13, 25-43.

Pisoni, D. B. Auditory and phonetic memory codes in the discrimination of consonants and vowels. Perception \& Pyschophysics, 1973, 13, 253-260.

Strange, W., \& Jenkins, J. J. The role of linguistic experience in the perception of speech. In H. L. Pick, Jr., \& R. D. Walk (Eds.), Perception and experience. New York: Plenum, in press. Studdert-Kennedy, M. Speech perception. In N. J. Lass (Ed.), Contemporary issues in experimental phonetics. New York: Academic Press, 1976. Pp. 243-293.

\section{NOTES}

1. Using oral stops, Mattingly, Liberman, Syrdal, and Halwes (1971) found little evidence of categorical perception for mirrorimage reversals of two-formant $\mathrm{CV}$ pattern. These results are uninterpretable, however, since the offset characteristics of the reversed patterns were acoustically quite different from naturally produced final stops and sounded quite unnatural. In the case of mirror-image synthetic nasals, the nasal resonance is sustained past the of fset of oral formants (as is the case for naturally spoken nasals), producing a more natural sounding pattern. Because of this, highly identifiable final nasals can be generated using exact mirror images of the cues for place-of-articulation of initial nasals, even though naturally produced initial and final nasals are not simple mirror images of one another.

2. Many subjects failed to identify the stimuli consistently, which suggests that the synthetic tokens used in these studies were poor representations of the phonemes. It is not possible, therefore, to assess with any confidence the correspondence (or lack of it) between discrimination and identification performance necessary for determining if nasals are perceived categorically. 
3. Some phonologists might object to this statement, saying that [n] does not occur initially because its underlying phonological form is $/ \mathrm{ng} /$. According to this description, there is no "hole in the code" at the phonological level, since /ng/, /nd/, and $/ \mathrm{mb} /$ all fail to occur initially. Thus, the "hole" is phonetic, not phonological, as the term "code" implies. For the purposes of this experiment, we are concerned with the phonotactic constraints on the surface forms $[\mathrm{m}],[\mathrm{n}],[\mathrm{n}]$, and how they may affect perception of the acoustic patterns specifying these phonetic units.

4. Syllable-final nasals were always presented first, since the sound $/ y /$ can occur in the final position. By exposing the listeners to this condition first, we hoped that the added practice would increase the reliability of the data for the syllable-initial nasals, and in particular the data for $/ \eta /$. We assumed that if the order of presentation biased the results at all, it would be in a direction counter to our hypothesis that syllable-final nasals would be perceived better than syllable-initial nasals. That is, practice on syllable-final nasals might improve performance on syllable-initial nasals.

5. The one-step functions show the percent correct discrimination of stimuli that were one step apart in the stimulus series (e.g., Pairs 1-2, 2-3, . . , 9-10). The two-step functions show the discrimination of pairs of stimuli that were two steps apart (e.g., Pairs 1-3, 2-4, . , 8-10).

6. The formula

$$
P(i, j)=\frac{1+\left(m_{i}-m_{j}\right)^{2}+\left(n_{i}-n_{j}\right)^{2}+\left(\eta_{i}-\eta_{j}\right)^{2}}{3} .
$$

gives the probability of the subject's correctly discriminating stimulus $i$ from stimulus $j$ as a function of six different probabilities obtained from his identification functions:

$$
\begin{aligned}
& m_{i}=\text { the probability of identifying stimulus } i \text { as an } m \\
& n_{i}=\text { the probability of identifying stimulus } i \text { as an } n \\
& \eta_{i}=\text { the probability of identifying stimulus } i \text { as an } \eta \\
& m_{j}=\text { the probability of identifying stimulus } j \text { as an } m \\
& n_{j}=\text { the probability of identifying stimulus } j \text { as an } n \\
& \eta_{j}=\text { the probability of identifying stimulus } j \text { as an } \eta
\end{aligned}
$$

This formula for the probability of discriminating correctly in an oddity discrimination task is derived in the same way that Liberman, Harris, Hoffman, and Griffith (1957) derived their formula for $\mathrm{ABX}$ discrimination.

7. The chi-square test of goodness of fit is extremely insensitive. However, there is no consistent direction of difference between goodiness of fit on forward and backward functions.

8. Subjects in this experiment took twice as many tests in the same number of sessions as in Experiment 1. They took the two identification and four discrimination tests for each condition in one session instead of over two sessions. In addition, all subjects heard the first discrimination and identification tapes before the second discrimination and identification tapes. The order of presentation of these tapes was not randomized as in Experiment 1 . Note, however, that the sessions were counterbalanced with respect to whether subjects heard nasals first or stops first.

9. Stimuli used by Miller and Eimas (1977) also distinguished place-of-articulation among nasals by differences in F2 and F3 transitions only. While their stimuli did include upper nasal resonances, they were fixed for all stimuli.

(Received for publication August 1, 1977; revision accepted December 28,1977 .) 